\title{
GSTP1 rs1695 is associated with both hematological toxicity and prognosis of ovarian cancer treated with paclitaxel plus carboplatin combination chemotherapy: a comprehensive analysis using targeted resequencing of 100 pharmacogenes
}

\author{
Tomoko Yoshihama, Koya Fukunaga', Akira Hirasawa ${ }^{2}$, Hiroyuki Nomura ${ }^{2}$, \\ Tomoko Akahane ${ }^{2}$, Fumio Kataoka², Wataru Yamagami², Daisuke Aokiं ${ }^{2}$ and Taisei \\ Mushiroda $^{1}$ \\ ${ }^{1}$ Laboratory for Pharmacogenomics, RIKEN Center for Integrative Medical Sciences, Yokohama, Japan \\ ${ }^{2}$ Department of Obstetrics and Gynecology, Keio University School of Medicine, Tokyo, Japan \\ Correspondence to: Taisei Mushiroda, email: mushiroda@riken.jp \\ Keywords: pharmacogenomics; carboplatin; ovarian cancer; next-generation sequencer; targeted resequencing \\ Received: April 07, $2018 \quad$ Accepted: June 13,2018 Published: July 03, 2018 \\ Copyright: Yoshihama et al. This is an open-access article distributed under the terms of the Creative Commons Attribution License \\ 3.0 (CC BY 3.0), which permits unrestricted use, distribution, and reproduction in any medium, provided the original author and \\ source are credited.
}

\section{ABSTRACT}

Purpose: To find genetic variants that predicted toxicity and/or efficacy of paclitaxel plus carboplatin combination therapy (TC therapy).

Patients and methods: In a retrospective case-control study, we analyzed $\mathbf{3 2 0}$ patients who had received TC therapy for gynecological cancers (ovarian, fallopian tube, peritoneal, uterine, and cervical cancers) and collected their germline DNA. We performed a comprehensive pharmacogenomic analysis using a targeted resequencing panel of 100 pharmacogenes. For 1,013 variants passing QC, case-control association studies and survival analyses were conducted.

Results: GSTP1 rs1695 showed the smallest p value for hematotoxicity association, and the ${ }^{105}$ Ile wild type allele had a significantly higher risk of severe hematotoxicity (neutropenia G4, thrombocytopenia $\geq \mathbf{G 3}$ and anemia $\geq \mathbf{G 3}$ ) than the ${ }^{105} \mathrm{Val}$ allele $(p=0.00034$, odds ratio $=5.71$ ( $95 \%$ confidence interval: $1.77-18.44)$ ). Next, we assessed 5-year progression-free survival (PFS) and overall survival (OS) in $\mathbf{5 6}$ advanced ovarian cancer patients who received tri-weekly TC as a first-line chemotherapy. Patients with the ${ }^{105} \mathrm{Ile} /{ }^{105} \mathrm{Ile}$ genotype showed significantly better PFS $(p=0.00070)$ and OS $(p=0.0012)$ than those with the ${ }^{105} \mathrm{Ile} /{ }^{105} \mathrm{Val}$ or ${ }^{105} \mathrm{Val} /{ }^{105} \mathrm{Val}$ genotype.

Conclusion: Our study indicates that the GSTP1 rs1695 ${ }^{105} \mathrm{Ile} /{ }^{105} \mathrm{Ile}$ genotype is associated with both severe hematotoxicity and high efficacy of TC therapy, identifying a possible prognostic indicator for patients with TC therapy.

\section{INTRODUCTION}

Paclitaxel plus carboplatin combination chemotherapy (TC therapy) is an important treatment for gynecological malignancies, including ovarian, peritoneal, fallopian tube, uterine, and cervical cancers. In particular, for ovarian cancer, TC therapy is currently the standard first-line chemotherapy or platinum-sensitive recurrent chemotherapy
$[1,2]$, and carboplatin is considered a key drug in its activity. More recently, a modified administration schedule of TC therapy has been developed, which includes administration of paclitaxel every week (dose-dense TC therapy) [3]. However, the prognosis of patients with ovarian cancer is still poor, especially in the advanced stage [4].

In general, conventional antitumor drugs have a narrow therapeutic window, with a high frequency of 
adverse drug reactions (ADRs). TC therapy is often associated with serious hematological toxicities, such as neutropenia, thrombocytopenia, and anemia $[1,2]$. These toxicities can be a dose-limiting factor, potentially affecting patient quality of life. It is known that the severity or frequency of these adverse events varies between individuals clinically [5]. Therefore, efforts have been made in pharmacogenomic analyses to explore the single-nucleotide polymorphisms (SNPs) associated with toxicity and efficacy of taxanes and platinum agents. Several candidate genes have been reported, such as efflux transporters of the ATP binding cassette (ABC) family, including $A B C B 1, A B C C 2$, and $A B C G 2$ [6-10]; influx transporters of the solute carrier (SLC) family, including SLCO1B3 [8, 11]; members of the cytochrome p450 (CYP) family, including CYP3A4, CYP3A5, and CYP2C8 [12-15]; genes involved in detoxification, including GSTP1, GSTT1, and GSTM1 [16-19]; and genes involved in base-excision DNA repair, including ERCC1 and XRCC1 [19-21]. However, to date, no genetic factors have been established as useful biomarkers of toxicity or efficacy of TC therapy.

In our current study, we performed a comprehensive pharmacogenomic analysis by targeted resequencing of 100 pharmacogenes, using a bench top next-generation sequencer. The aim of our study is to identify genetic variants that are associated with the toxicity and efficacy of TC therapy, so that we are able to predict the likelihood of severe toxicity or efficacy in patients before treatment.

\section{RESULTS}

\section{Patient characteristics}

The characteristics of the 320 patients who received TC therapy for gynecological cancers are shown in Table 1. Fifty patients were classified as ADR group and 270 patients were controls. The median age was 54.5 years (range: $35-80$ ) in the ADR group and 54 years (range: $27-$ $80)$ in the control group. Regarding possible confounding factors, including age, tumor stage by FIGO classification, regimen, and total number of cycles in the observed TC treatment period, we found no significant differences between the ADR group and control groups (Table 1).

\section{Targeted resequencing}

By the targeted resequencing of 320 subjects, we obtained an output of $35.8 \mathrm{Gbp}$ of sequence data. After a data mapping to human reference sequence (build hg19), on average, $98.5 \%$ of the targeted exonic regions $(159,347 \mathrm{bp})$ were covered by at least $20 \times$ depth. An average read depth of the targeted regions was $289 \times$. After a QC filtering based on depth $<20 \times$ and allele balance $<20 \%$, 1,029 variants were identified. After filtering variants of minor allele frequencies of $\geq 0.001$, missing genotype rates of $<10 \%$ and $p$-values less than the cutoff value of $<1.0 \times 10^{-6}$ by the Hardy-Weinberg equilibrium test, 1,013 variants consisting of 11 frameshift deletions, 12 frameshift insertions, 5 nonframeshift deletions, 4 nonframeshift insertions, 601 nonsynonymous single nucleotide variants (SNVs), 23 stop-gain SNVs, 1 stoploss SNV and 356 synonymous SNVs were used for the further analysis.

\section{Case-control association study of hematological toxicity}

The Manhattan plot of the case-control association analyses is shown in Figure 1, and 20 nonsynonymous variants, which showed significant association with ADR grouping, are listed in Table 2. GSTP1 rs1695 (c.A342G, p.Ile105Val) showed the lowest p-value among them. The ${ }^{105}$ Ile allele (wild type) had a significantly higher risk of severe hematotoxicity than the ${ }^{105}$ Val allele did $(p=0.00034$, odds ratio=5.71 (95\%CI: 1.77-18.44)).

\section{Survival analysis}

Next, we compared the 5-year PFS (progression-free survival) and OS (overall survival) of advanced ovarian cancer patients between the GSTP1 rs1695 genotypes. The characteristics of the 56 patients who received tri-weekly TC therapy as first-line therapy are shown in Table 3 , and those of the 55 patients receiving dose-dense TC therapy are shown in Supplementary Table 1. The median followup duration was 1764 days (range; 141-5661 days) in the tri-weekly TC group, and 884 days (190-1548 days) in the dose-dense TC group. No patient in the dose-dense TC group reached 5 years of follow-up, because dosedense TC therapy started in January 2012 in our hospital. The median PFS of tri-weekly TC therapy was 924 days $(55-5661$ days $)$ in the ${ }^{105} \mathrm{Ile} /{ }^{105} \mathrm{Ile}$ group $(\mathrm{n}=47)$ and 417 days (27-905 days) in the ${ }^{105} \mathrm{Ile} /{ }^{105} \mathrm{Val}+{ }^{105} \mathrm{Val} /{ }^{105} \mathrm{Val}$ group $(n=9)$. The median OS of tri-weekly TC therapy was not reached (141-5661 days) in the ${ }^{105} \mathrm{Ile} /{ }^{105} \mathrm{Ile}$ group and was 926 days (177-5077 days) in the ${ }^{105} \mathrm{Ile} /{ }^{105} \mathrm{Val}+$ ${ }^{105} \mathrm{Val} /{ }^{105} \mathrm{Val}$ group. The Kaplan-Meier curves for 5-year PFS and OS of tri-weekly TC therapy are shown in Figure 2. Both 5-year PFS and OS in the ${ }^{105} \mathrm{Ile} /{ }^{105} \mathrm{Ile}$ group were significantly better than those in the ${ }^{105} \mathrm{Ile} /{ }^{105} \mathrm{Val}+$ ${ }^{105} \mathrm{Val} /{ }^{105} \mathrm{Val}$ group were $(\mathrm{p}=0.00070$ and $\mathrm{p}=0.0012$ for PFS and OS, respectively). The PFS and OS with dose-dense TC therapy showed no significant differences between the ${ }^{105} \mathrm{Ile} /{ }^{105} \mathrm{Ile}(\mathrm{n}=40)$ and the ${ }^{105} \mathrm{Ile} /{ }^{105} \mathrm{Val}+{ }^{105} \mathrm{Val} /{ }^{105} \mathrm{Val}$ $(n=15)$ groups $(p=0.44$ and $p=0.28$ for PFS and OS, respectively, Supplementary Figure 1).

\section{DISCUSSION}

To date, many researchers have been searching for SNPs associated with susceptibility to taxane- or platinum 
Table 1: Patient characteristics of the 320 patients

\begin{tabular}{|c|c|c|c|c|}
\hline & & & ents & P value \\
\hline & & $\begin{array}{l}\text { ADR group } \\
\quad(n=50)\end{array}$ & $\begin{array}{c}\text { Control group } \\
\quad(n=270)\end{array}$ & \\
\hline Age, years & Median & 54.5 & 54 & 0.093 \\
\hline & Range & $35-80$ & $27-80$ & \\
\hline Cancer & Ovary & $27(54 \%)$ & $166(61 \%)$ & \\
\hline & Uterus & $17(34 \%)$ & $80(30 \%)$ & \\
\hline & Cervix & $2(4 \%)$ & $8(3 \%)$ & \\
\hline & Ovary+uterus & $4(8 \%)$ & $13(5 \%)$ & \\
\hline & Ovary+cervix & $0(0 \%)$ & $3(1 \%)$ & \\
\hline Stage & I & $18(36 \%)$ & $97(36 \%)$ & 0.54 \\
\hline & II & $6(12 \%)$ & $19(7 \%)$ & $(\mathrm{I}+\mathrm{II}$ vs III+IV) \\
\hline & III & $21(42 \%)$ & $114(42 \%)$ & \\
\hline & IV & $5(10 \%)$ & $40(15 \%)$ & \\
\hline Regimen & Dose-dense & $12(24 \%)$ & $55(20 \%)$ & 0.57 \\
\hline & Tri-weekly & $38(76 \%)$ & $215(80 \%)$ & \\
\hline Total number of cycles & 1 & $0(0 \%)$ & $5(2 \%)$ & 0.86 \\
\hline & 2 & $0(0 \%)$ & $10(4 \%)$ & \\
\hline & 3 & $3(6 \%)$ & $9(3 \%)$ & \\
\hline & 4 & $3(6 \%)$ & $7(3 \%)$ & \\
\hline & 5 & $6(12 \%)$ & $12(4 \%)$ & \\
\hline & 6 & $35(70 \%)$ & $204(76 \%)$ & \\
\hline & 7 & $0(0 \%)$ & $2(1 \%)$ & \\
\hline & 8 & $2(4 \%)$ & $13(5 \%)$ & \\
\hline & 9 & $1(2 \%)$ & $8(3 \%)$ & \\
\hline & Median & 6 & 6 & \\
\hline Treatment & 1st-line & $45(90 \%)$ & $253(94 \%)$ & \\
\hline & Recurrent & $5(10 \%)$ & $17(6 \%)$ & \\
\hline
\end{tabular}

ADR: adverse drug reaction

agent-related toxicities, but, unfortunately, most results have not been replicated [6-24]. Consequently, there have been no established genetic markers that predict the toxicity or efficacy of these drugs, regardless of their clinical importance in the treatment of various cancers. Our current study has some advantages compared with those of previous studies. First, we only included patients receiving paclitaxel plus carboplatin combination chemotherapy, which means that it is possible to eliminate consideration of effects of other taxanes or platinum agents, such as docetaxel, cisplatin and oxaliplatin. Second, we adopted a method of targeted resequencing of 100 notable pharmacokinetics-related genes using a nextgeneration sequencer, since candidate gene approaches might miss other significant associations. Third, we recruited 320 Japanese patients with detailed clinical data in our hospital. Some previous studies were performed in small sample size, less than one hundred patients, which might have insufficient statistical power to detect significant association.

The case-control association analysis indicated that 20 variants were significantly associated with severe hematological toxicity, with GSTP1 rs1695 showing the lowest $p$-value among them $(p=0.00034)$. Glutathione S-transferase P1 (GSTP1) has been shown to metabolize carboplatin in vitro [25], and in our results, the ${ }^{105}$ Ile allele was associated with a higher risk of severe hematotoxicity than the ${ }^{105}$ Val allele was (odds ratio=5.71 (95\%CI: 


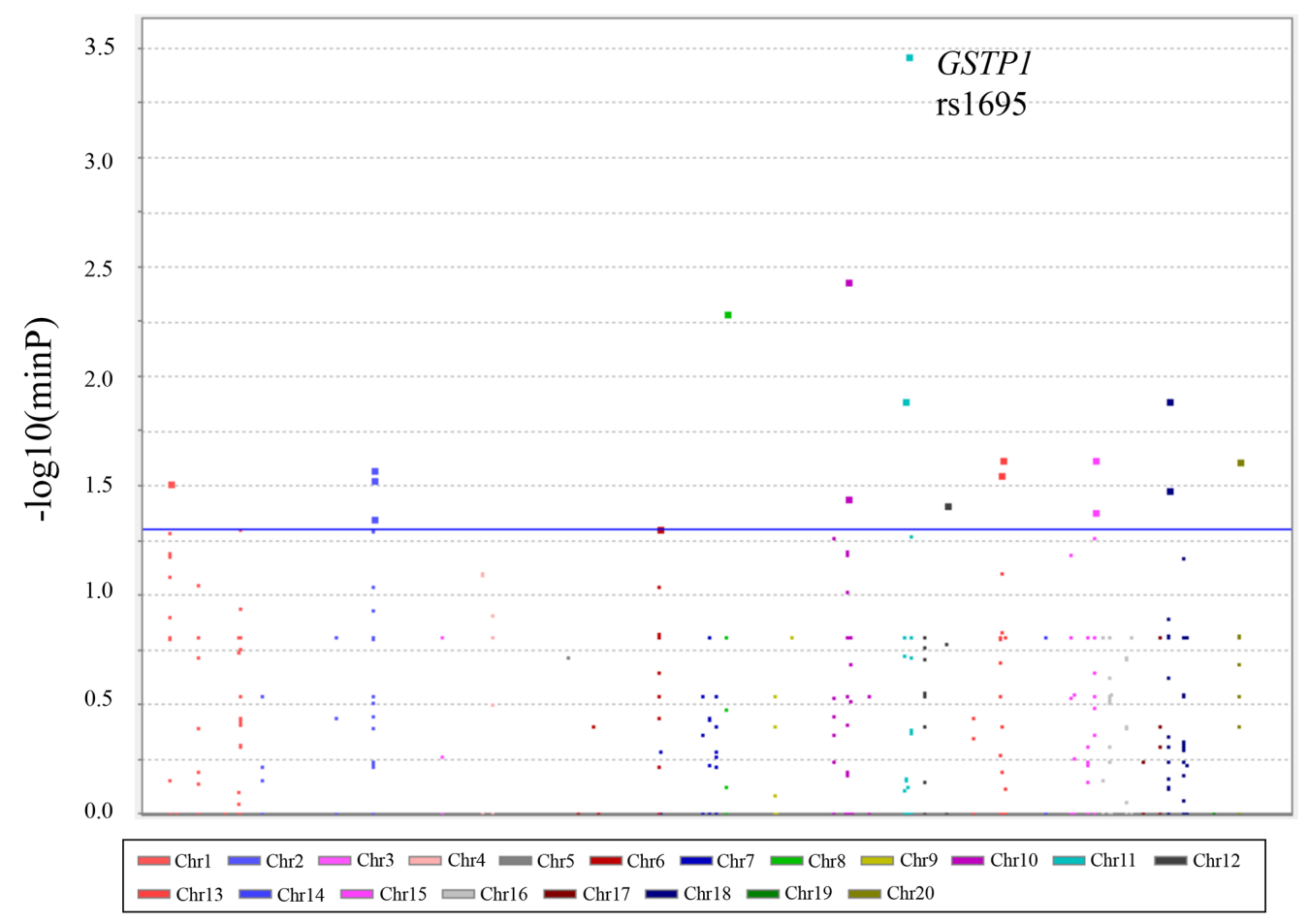

Chromosome number

Figure 1: Manhattan plot with hematological toxicities. Manhattan plot for case-control association studies of hematological toxicity induced by paclitaxel plus carboplatin combination chemotherapy in Japanese gynecological cancer patients. The $-\log _{10}(\mathrm{minimal}$ $\mathrm{p}$ value) versus chromosome position is plotted for each variant. The blue line indicates the significance level at $\mathrm{p}=0.05$.

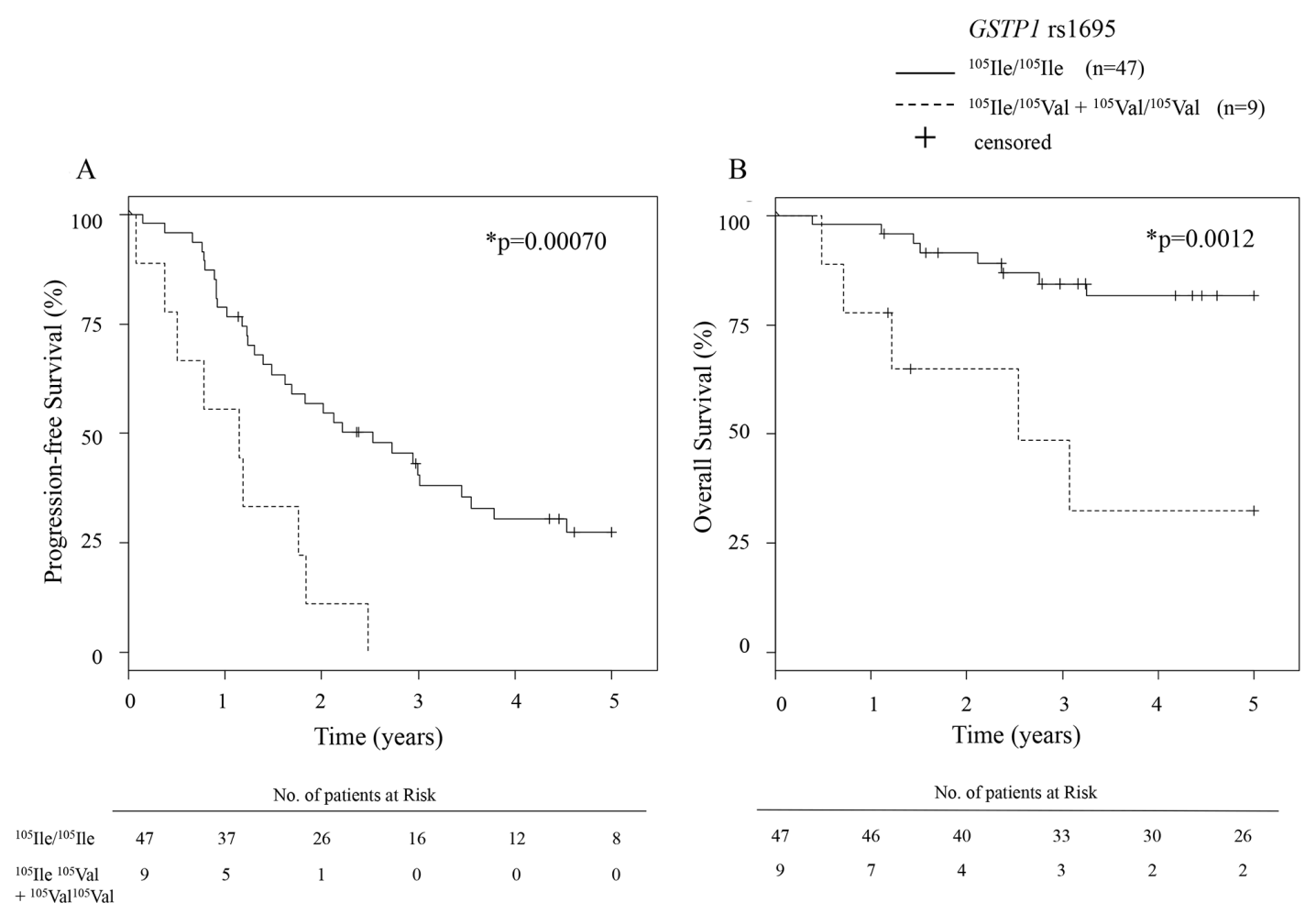

Figure 2: Kaplan-Meier curve for 5-year PFS and OS of tri-weekly TC patients. Kaplan-Meier curves of (A) progression free survival (PFS) and (B) overall survival (OS) of advanced ovarian carcinoma patients who received tri-weekly TC therapy according to GSTP1 rs1695 genotypes. The risk tables are shown below each plot. TC, paclitaxel plus carboplatin combination. 
Table 2: Twenty nonsynonymous variants which showed significant association

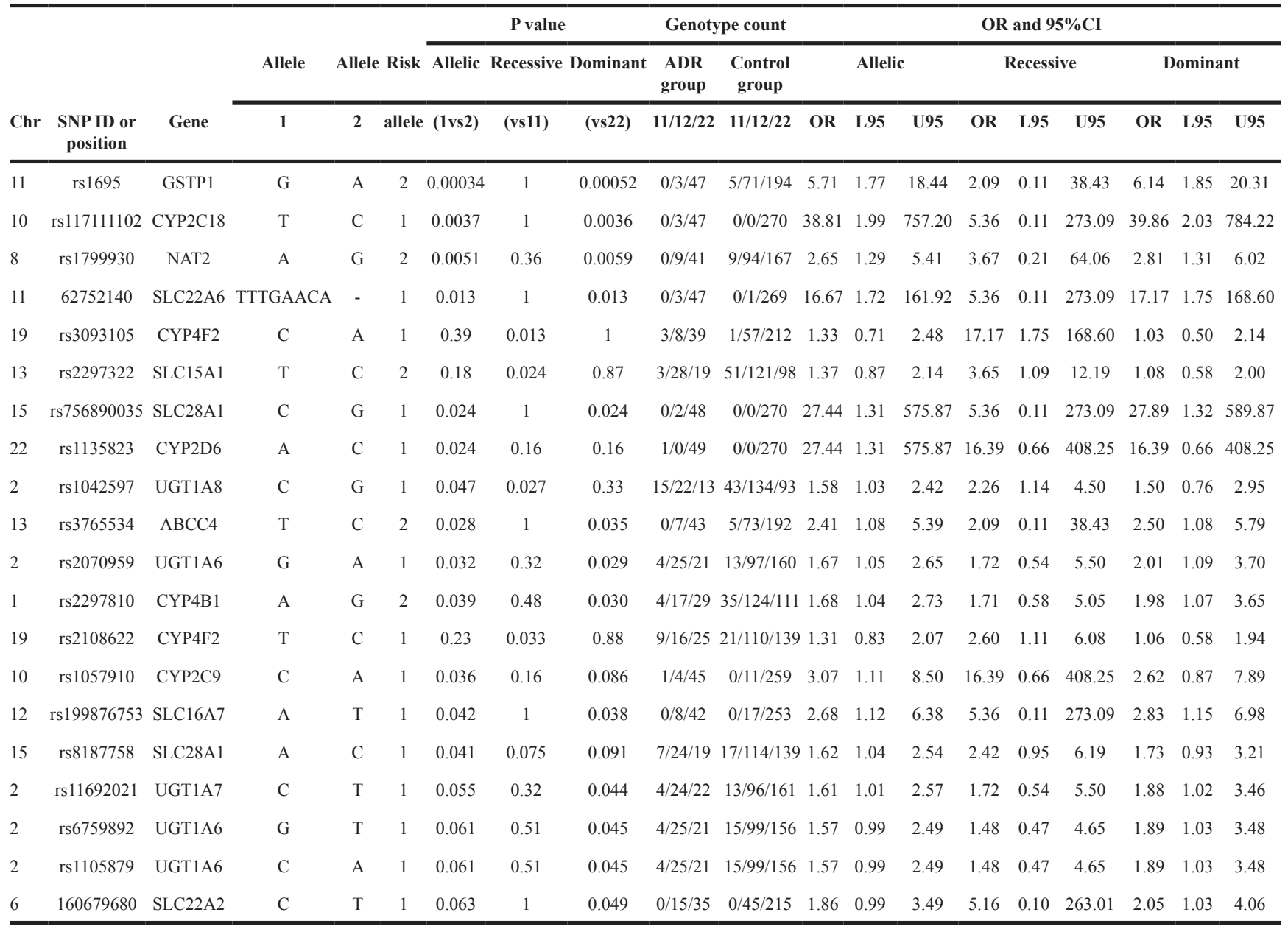

"Chr: chromosome number, ADR: adverse drug reaction, OR: odds ratio, CI: confidence interval, L95: lower 95\% confidence interval, U95: upper 95\% confidence interval.

1.77-18.44)). We defined severe hematological toxicity as having decreased neutrophil count, platelet count, and hemoglobin concentration. This was based on our assumption that several types of adverse events should be observed simultaneously if they occurred due to the increased drug concentration that was caused by the pharmacogenetic variant. If so, this pharmacokinetic change could also have an influence on the antitumor effect. One of the strongest findings of our study is the association of rs1695 with treatment efficacy, as well as hematological toxicity. Our results indicate that, for advanced ovarian cancers treated with tri-weekly TC, the ${ }^{105} \mathrm{Ile} /{ }^{105} \mathrm{Ile}$ genotype showed significantly better PFS and OS than the ${ }^{105} \mathrm{Ile} /{ }^{105} \mathrm{Val}$ and ${ }^{105} \mathrm{Val} /{ }^{105} \mathrm{Val}$ genotypes did. This result was not observed in the dose-dense TC group, likely because of the shorter observation period and the censoring of many patients. From these results, we were able to develop a model to explain the effects of the genetic variant on the drug efficacy and toxicity (Figure $3)$. The ${ }^{105} \mathrm{Ile} /{ }^{105} \mathrm{Ile}$ genotype had a lower carboplatin- detoxifying ability, resulting in high carboplatin exposure systematically or locally, which increased both treatment efficacy and risk of hematotoxicity. This model would be of interest to clinicians, especially from a precision-medicine standpoint. If this model is verified, the prognosis of ovarian cancer patients with GSTP1 ${ }^{105} \mathrm{Ile} /{ }^{105} \mathrm{Val}$ or ${ }^{105} \mathrm{Val} /{ }^{105} \mathrm{Val}$ genotypes could be improved by simply adjusting the carboplatin dose-intensity to optimal efficacy levels, with appropriate management of hematotoxicity.

Glutathione S-transferases (GSTs) are a multigene family of enzymes that catalyze the conjugation of glutathione (GSH) to a variety of electrophilic xenobiotics, eventually forming a mercapturic acid to be excreted into the urine $[26,27]$. GSTP1 is a GST isoenzyme, which plays an important role in detoxifying carcinogens, metabolizing chemotherapeutic agents, and regulating the cell cycle and apoptosis [28, 29]. The GSTP1 gene locus is known to be polymorphic, and three haplotypes have been identified so far, GSTPI ${ }^{*} A\left({ }^{105} \mathrm{Ile}^{114} \mathrm{Ala}\right)$, GSTPI ${ }^{*} B$ 
Table 3: Patient characteristics of the advanced ovarian cancer patients who received tri-weekly TC therapy

\begin{tabular}{|c|c|c|c|c|}
\hline & & & patients & P value \\
\hline & & $\begin{array}{c}{ }^{105} \mathrm{Ile} /{ }^{105} \mathrm{Ile} \\
(\mathrm{n}=47)\end{array}$ & $\begin{array}{c}{ }^{105} \mathrm{Ile} /{ }^{105} \mathrm{Val}+{ }^{105} \mathrm{Val} /{ }^{105} \mathrm{Val} \\
(\mathrm{n}=9)\end{array}$ & \\
\hline Age, years & Median & 53 & 51 & 0.759 \\
\hline & Range & $32-73$ & $27-78$ & \\
\hline Cancer & Ovary & $43(91 \%)$ & $9(100 \%)$ & \\
\hline & Ovary+uterus & $4(9 \%)$ & 0 & \\
\hline Stage & III & $38(81 \%)$ & $5(56 \%)$ & 0.189 \\
\hline & IV & $9(19 \%)$ & $4(44 \%)$ & \\
\hline & Complete & $22(47 \%)$ & $4(44 \%)$ & 1.000 \\
\hline Debulking status & Optimal & $17(36 \%)$ & $0(0 \%)$ & (complete vs others) \\
\hline & Suboptimal & $8(17 \%)$ & $5(56 \%)$ & \\
\hline & Poorly differentiated & $5(11 \%)$ & $3(33 \%)$ & \\
\hline & Serous & $23(49 \%)$ & $4(44 \%)$ & \\
\hline Histology & Endometrioid & $7(15 \%)$ & $0(0 \%)$ & \\
\hline & Clear & $3(6 \%)$ & $0(0 \%)$ & \\
\hline & Others & $9(20 \%)$ & $2(22 \%)$ & \\
\hline
\end{tabular}

$\left({ }^{105} \mathrm{Val}^{114} \mathrm{Ala}\right)$, and $G S T P 1{ }^{*} C\left({ }^{105} \mathrm{Val}^{114} \mathrm{Val}\right)[30]$. Since the ${ }^{114}$ Val (rs1138272, $\mathrm{T}$ allele) frequency in the Japanese population is very low, and no patient had this variant in our population, the effect of ${ }^{114} \mathrm{Val}$ could be ignored in the current study.

Many studies have shown that GSTP1 can detoxify cisplatin and carboplatin [25, 31-33], and some investigators have discussed the association between GSTP1 and cisplatin resistance [34-36]. The functional effect of rs1695 has also been well studied [25, 27, 30, $32,37]$. Interestingly, the effect of rs1695, with an amino acid substitution in the substrate-binding site, differed depending on the substrates involved [25]. Ishimoto et al. reported that the cytotoxicities induced by cisplatin and carboplatin toward GSTP1 ${ }^{105} \mathrm{Ile}$-expressing Escherichia coli were higher than those of the ${ }^{105} \mathrm{Val}$ mutant [25]. In another study, Peklak-Scott et al. found that the conjugation of cisplatin and GSH catalyzed by GSTP1

\section{Platinum/glutathione conjugation}
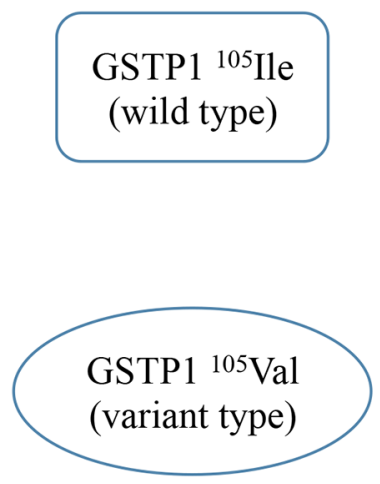
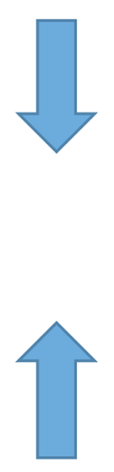

Exposure of carboplatin (local or systemic)
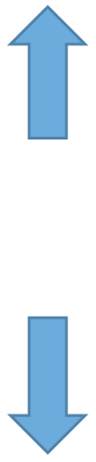

Toxicity

Efficacy
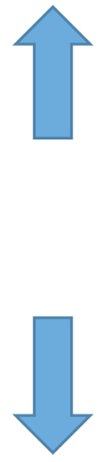

Figure 3: Our model regarding the effect of GSTP1 rs1695 variants on each pharmacokinetic parameter. In our model, the platinum-detoxifying activity of GSTP1 is increased with the $\mathrm{rs} 1695{ }^{105}$ Val variant, thus lowering exposure to carboplatin, lowering toxicity, and lowering efficacy. 
${ }^{105}$ Ile decreased compared to that of ${ }^{105}$ Val [32]. These previous reports showed that the platinum-detoxifying ability of GSTP1 ${ }^{105}$ Ile was lower than that of ${ }^{105} \mathrm{Val}$, strongly supporting our model.

However, the association of GSTP1 rs1695 genotypes with the clinical outcomes of platinum-based chemotherapy is still controversial. Some research groups reported the similar findings to ours [19, 38, 39], while others showed the opposite direction of effects of rs1695 [40, 41]. Kim et al. reported that the GSTP1 rs $1695{ }^{105} \mathrm{Ile} /{ }^{105} \mathrm{Ile}$ genotype showed higher rates of grade 3 or 4 hematological toxicity than the ${ }^{105} \mathrm{Ile} /{ }^{105} \mathrm{Val}$ and ${ }^{105} \mathrm{Val} /{ }^{105} \mathrm{Val}$ genotypes did [38]. In their study, 96 out of 118 patients $(81.3 \%)$ received chemotherapy with paclitaxel and carboplatin, $13(11.1 \%)$ with docetaxel and carboplatin, and $9(7.6 \%)$ with paclitaxel and cisplatin. Similarly, Lambrechts et al. reported the ${ }^{105} \mathrm{Ile}$ allele to have a higher risk of colony stimulating factor (CSF) use than the ${ }^{105}$ Val allele did [39]. Their study included $266(82.6 \%)$ patients receiving carboplatin and paclitaxel and $56(17.4 \%)$ patients receiving carboplatin monotherapy. They specified their criteria for CSF use as follows: neutropenia grade 4 together with fever $>38^{\circ} \mathrm{C}$ or neutropenia grade 4 for a minimum of 5 consecutive days. In addition, Khrunin et al. reported similar results of ovarian cancer survival revealing that the ${ }^{105} \mathrm{Ile} /{ }^{105} \mathrm{Ile}$ genotype had a significantly increased PFS compared with that of the ${ }^{105} \mathrm{Ile} /{ }^{105} \mathrm{Val}$ or ${ }^{105} \mathrm{Val} /{ }^{105} \mathrm{Val}$ genotype, although their patients received cisplatin-cyclophosphamide regimen [19]. Although some differences existed, overall, our findings corroborated the results of these studies, thus supporting our model strongly. Moreover, our study provides important insights into the treatment of ovarian cancer with TC therapy because there has been, as far as we know, no report that evaluated association of genetic polymorphisms with both toxicity and efficacy of platinum-based anticancer reagents using clinical information of the same patients. We believe that the present findings shed new light on safer and more appropriate chemotherapy for ovarian cancer.

Our model is interesting because it also may explain the ethnic differences in TC therapy efficacy. In the JGOG3016 study [3], the median PFS and OS of tri-weekly TC therapy in Japanese ovarian cancer patients were 17.2 months and not reached, respectively. However, in the GOG-0218 study [42], the investigators reported the median PFS and OS as 10.3 and 39.3 months, respectively, in a population that was composed of nonHispanic white (84.2\%), Asian (6.6\%), non-Hispanic black (4.0\%), Hispanic (3.4\%), and others (1.9\%). The Japanese population seems to be more responsive to TC therapy. Interestingly, ethnic differences were observed in the allele frequency of rs $1695{ }^{105} \mathrm{Val}$, with the Japanese population showing the lowest frequency (0.101), according to the 1000 Genomes Project (http://www.internationalgenome.org/). The higher frequency of wild-type $\left({ }^{105} \mathrm{Ile} /{ }^{105} \mathrm{Ile}\right)$ in Japanese may account for the ethnic differences above. To the best of our knowledge, our study is the first to report the association of TC therapy efficacy with GSTP1 rs1695 in Japanese patients.

Our study had some limitations. First, it was designed as a retrospective case-control study, and there are inherent biases with this type of study. Second, the sample size was small in the survival analysis because only advanced ovarian cancer patients receiving triweekly TC or dose-dense TC therapy as first-line chemotherapy had been included for accurate estimation of prognosis. In order to overcome the limitations, the best way is to conduct a replication study using an independent cohort for confirmation of the associations. Therefore, further prospective analyses, including generating pharmacokinetic data or performing replication studies with larger populations, are required in order to firmly establish our model.

In conclusion, we performed a comprehensive pharmacogenomic analysis, using a targeted resequencing panel of 100 pharmacogenes. Our results reveal that GSTP1 rs1695, known as a functional variant, is associated with both paclitaxel and carboplatin hematotoxicity, and the efficacy of ovarian cancer treatment. Several prior reports in vivo and in vitro were consistent with our results. We believe that this clinically interesting association will be verified and understood more precisely in the future.

\section{MATERIALS AND METHODS}

\section{Patients}

Keio Women's Health Biobank (KWB, Tokyo, Japan) was started in 2006 to reposit frozen tissue, formalin-fixed paraffin-embedded (FFPE) tissue, germline DNA, serum, and ascites samples from gynecological patients. This biobank project was approved by the ethics committee of the School of Medicine, Keio University, and written informed consent was obtained from all patients before enrollment.

We found 320 adult female patients, with germline DNA samples available in the KWB, who received at least one cycle of TC therapy for ovarian, fallopian tube, peritoneal, uterine, or cervical cancer from January 1999 to August 2016. Patients who had uncontrolled serious complications were excluded. Clinical data about patient characteristics, ADR information, and data related to survival (i.e., date of recurrence, death, and last visit to the hospital) were collected from the medical records retrospectively. Disease had been confirmed by histologic examination, and the tumor stage had been assessed according to the 
International Federation of Gynecology and Obstetrics (FIGO) classification.

\section{Chemotherapy regimens}

All patients had received either tri-weekly TC or dose-dense TC therapy, and those TC therapies were performed as either first-line or recurrent treatments. Patients who had received chemotherapy regimen containing taxanes or platinum agents other than paclitaxel or carboplatin (e.g., combination therapy with docetaxel or cisplatin) were excluded. Patients with monotherapy of paclitaxel or carboplatin were also excluded from this study. Tri-weekly TC therapy included administration of paclitaxel $\left(175-180 \mathrm{mg} / \mathrm{m}^{2}\right)$ and carboplatin (AUC $6.0 \mathrm{mg} \cdot \mathrm{min} / \mathrm{mL}$ ) on day 1, which was repeated every 3 weeks. Dose-dense TC therapy, on the contrary, included administration of paclitaxel $\left(80 \mathrm{mg} / \mathrm{m}^{2}\right)$ on day 1,8 , and 15 , and carboplatin (AUC $6.0 \mathrm{mg} \cdot \mathrm{min} / \mathrm{mL}$ ) on day 1 , which was repeated every 3 weeks. Appropriate dose reduction was performed for febrile neutropenia, G4 neutropenia that lasted $\geq 7$ days, G4 thrombocytopenia, and non-hematological toxicities $\geq$ G3. Granulocyte-colony stimulating factor (G-CSF) was applied at the discretion of the attending physician, mostly for the patients with febrile neutropenia or prolonged G4 neutropenia. Red blood cell transfusion was also considered if the patient showed anemia $\geq G 3$ and clinical symptoms. Although the standard treatment period consisted of 6 cycles, it could be discontinued if the patient experienced severe adverse events after an appropriate dose-reduction or postponement, or it could be continued beyond 6 cycles if the attending physician deemed extension beneficial.

\section{Adverse drug reaction evaluation}

Complete blood counts had been routinely performed to assess hematological toxicity during TC therapy, and their grades were scored according to the Common Terminology Criteria for Adverse Events, version 4.0. The monitoring period for ADR was from the first administration day to 6 weeks after the final administration of either paclitaxel or carboplatin. The worst grade for neutropenia, thrombocytopenia, and anemia during the treatment period was recorded. We divided the patients based on the severity of hematotoxicity as follows: patients who developed neutropenia G4, thrombocytopenia $\geq$ G3, and anemia $\geq \mathrm{G} 3$ in one treatment period were designated the "ADR group", and the other patients were designated the "Control group". Patients exposed to several TC therapies (e.g., first-line therapy as adjuvant chemotherapy and second-line therapy for the recurrence) were only required to meet the hematological toxicity criteria indicated above during one therapy regimen to be classified into the "ADR group."

\section{DNA extraction}

Peripheral blood samples had been obtained from patients and stored at $-80^{\circ} \mathrm{C}$. Genomic DNA was extracted from peripheral lymphocytes using a commercial kit (QIAamp DNA Blood Mini Kit, Qiagen, Hilden, Germany), following manufacturer's instructions, and stored at $4^{\circ} \mathrm{C}$ until analysis.

\section{Targeted resequencing of $\mathbf{1 0 0}$ pharmacogenes}

Targeted resequencing of 100 pharmacogenes, which included 37 transporters, 30 cytochrome P450 (CYP) enzymes, 10 uridine diphosphate UDPglucuronosyltransferases (UGT), five flavin-containing monooxygenases (FMO), four glutathione S-transferases (GST), four sulfotransferases (SULT), and 10 additional genes was performed (Supplementary Figure 2). Of the 100 pharmacogenes, 88 genes are reported in "Clinical annotations" and/or "Variant annotations" of The Pharmacogenetics and Pharmacogenomics Knowledge Base (https://www.pharmgkb.org/), based on scientific review of papers describing association of the variants with ADRs and/or drug efficacy. We selected the remaining 12 genes (CYP4F3 [43, 44], CYP4F8 [43, 45], CYP4F12 [43, 46, 47], CYP4Z1 [48], CYP11A1 [49], CYP26A1 [50], NUDT1 [51, 52], SLC10A1 [53, 54], SLC22A9 [55, 56], SLC29A2 [57], SLC29A3 [58], and SLC46A1 [59]) because a single or multiple papers demonstrated the phenotypic impact of the variant. We enriched the targeted coding regions using multiplex PCR, and added dual barcodes to the PCR products to distinguish each sample. After purification and quantification of PCR products, the pooled libraries were sequenced using the MiSeq Reagent Kit v2 (Illumina, San Diego, CA, USA) with an output of $2 \times 250 \mathrm{bp}$. Sequence reads were aligned to the human reference genome (hg19) using Burrows-Wheeler Aligner (ver. 0.7.4) [60], and then variants were called according to the Genome Analysis Toolkit (GATK, version 3.5.0-g36282e4) [61], using Best Practice Variant Detection recommendations [62].

\section{Survival analysis}

We assessed 5-year PFS and OS as measures of treatment efficacy. For PFS and OS analysis, we focused on advanced ovarian cancer (stage III+IV) from the 320 patients who received tri-weekly $(n=56)$ or dose-dense TC $(n=55)$ therapy as first-line chemotherapy. We analyzed tri-weekly and dose-dense TC separately because previous reports had shown significantly better PFS and OS with dose-dense TC than with tri-weekly TC [3]. PFS was defined as the interval between the first day of TC therapy administration and the day of the first relapse, progression, or death. Relapse and progression were diagnosed by imaging or clinical symptoms. OS was defined as the interval between the first day of TC therapy administration and the day of death. 


\section{Statistical methods}

For the 1,013 variants passing QC, case-control association analyses comparing the ADR group with the control group were evaluated by Fisher's exact test using PLINK version 1.9 [63], considering allelic, dominant, and recessive genetic models. P-values $<0.05$ were considered to be statistically significant. A Manhattan plot was generated using the minimum p-value among the three genetic models for each variant. Five-year OS and PFS curves were plotted using the Kaplan-Meier method; differences between genotypes were analyzed using the log-rank test. Patients who survived or did not show progression during the observation period were censored at the last confirmation date. The data were analyzed using the freely available statistical software $\mathrm{R}$ version 3.3.2. To estimate the differences in patient characteristics between the ADR and control groups, we used a Student's $t$-test or Fisher's exact test.

\section{Abbreviations}

TC therapy - paclitaxel plus carboplatin combination therapy; ADRs - adverse drug reactions; GSTP1 Glutathione S-transferase P1; SNPs - single-nucleotide polymorphisms; PFS - progression-free survival; OS overall survival

\section{Author contributions}

Tomoko Yoshihama designed the study, carried out the experiments, performed data analysis and drafted the manuscript. Koya Fukunaga and Taisei Mushiroda contributed to analysis and interpretation of data and revised the manuscript. All other authors contributed to design the conception of the work, data collection and critically reviewed the manuscript. All authors approved the final version of the manuscript.

\section{ACKNOWLEDGMENTS}

We thank the patients and the supporting medical staff at Keio University Hospital for making this study possible. We are grateful to Prof. Yusuke Tanigawara for his cooperation as a bridge between Keio University and RIKEN, and also Ms. Tomomi Noda, Ms. Mika Okabe, Ms. Atsuko Fukushima, and Ms. Keiko Abe for their managements of the biobank and clinical data.

\section{CONFLICTS OF INTEREST}

The authors declare no conflicts of interest.

\section{FUNDING}

This work was supported by JSPS KAKENHI Grant Number 17K19611.

\section{REFERENCES}

1. du Bois A, Luck HJ, Meier W, Adams HP, Mobus V, Costa S, Bauknecht T, Richter B, Warm M, Schroder W, Olbricht $\mathrm{S}$, Nitz U, Jackisch C, et al. A randomized clinical trial of cisplatin/paclitaxel versus carboplatin/paclitaxel as firstline treatment of ovarian cancer. J Natl Cancer Inst. 2003; 95:1320-9. https://doi.org/10.1093/jnci/djg036.

2. Ozols RF, Bundy BN, Greer BE, Fowler JM, ClarkePearson D, Burger RA, Mannel RS, DeGeest K, Hartenbach EM, Baergen R. Phase III trial of carboplatin and paclitaxel compared with cisplatin and paclitaxel in patients with optimally resected stage III ovarian cancer: a Gynecologic Oncology Group study. J Clin Oncol. 2003; 21:3194-200. https://doi.org/10.1200/JCO.2003.02.153.

3. Katsumata N, Yasuda M, Takahashi F, Isonishi S, Jobo T, Aoki D, Tsuda H, Sugiyama T, Kodama S, Kimura E, Ochiai K, Noda K. Dose-dense paclitaxel once a week in combination with carboplatin every 3 weeks for advanced ovarian cancer: a phase 3, open-label, randomised controlled trial. Lancet. 2009; 374:1331-8. https://doi.org/10.1016/S0140-6736(09)61157-0.

4. Saito T, Katabuchi H. Annual Report of the Committee on Gynecologic Oncology, Japan Society of Obstetrics and Gynecology: Patient Annual Report for 2013 and Treatment Annual Report for 2008. J Obstet Gynaecol Res. 2016; 42:1069-79. https://doi.org/10.1111/jog.13043.

5. Sparreboom A, Verweij J. Advances in cancer therapeutics. Clin Pharmacol Ther. 2009; 85:113-7. https://doi.org/10.1038/clpt.2008.259.

6. Bergmann TK, Brasch-Andersen C, Green H, Mirza MR, Skougaard K, Wihl J, Keldsen N, Damkier P, Peterson C, Vach W, Brosen K. Impact of ABCB1 variants on neutrophil depression: a pharmacogenomic study of paclitaxel in 92 women with ovarian cancer. Basic Clin Pharmacol Toxicol. 2012; 110:199 204. https://doi.org/10.1111/j.1742-7843.2011.00802.x.

7. Kiyotani K, Mushiroda T, Kubo M, Zembutsu H, Sugiyama Y, Nakamura Y. Association of genetic polymorphisms in SLCO1B3 and ABCC2 with docetaxelinduced leukopenia. Cancer Sci. 2008; 99:967-72. https://doi.org/10.1111/j.1349-7006.2008.00765.x.

8. Awada Z, Haider S, Tfayli A, Bazarbachi A, El-Saghir NS, Salem Z, Shamseddine A, Taher A, Zgheib NK. Pharmacogenomics variation in drug metabolizing enzymes and transporters in relation to docetaxel toxicity in Lebanese breast cancer patients: paving the way for OMICs in low and middle income countries. Omics. 2013; 17:353-67. https://doi.org/10.1089/omi.2013.0019.

9. Tian C, Ambrosone CB, Darcy KM, Krivak TC, Armstrong DK, Bookman MA, Davis W, Zhao H, Moysich K, Gallion H, DeLoia JA. Common variants in ABCB1, ABCC2 and ABCG2 genes and clinical outcomes among women with advanced stage ovarian cancer treated with platinum and taxane-based chemotherapy: a Gynecologic 
Oncology Group study. Gynecol Oncol. 2012; 124:575-81. https://doi.org/10.1016/j.ygyno.2011.11.022.

10. Kus T, Aktas G, Kalender ME, Demiryurek AT, Ulasli M, Oztuzcu S, Sevinc A, Kul S, Camci C. Polymorphism of CYP3A4 and ABCB1 genes increase the risk of neuropathy in breast cancer patients treated with paclitaxel and docetaxel. Onco Targets Ther. 2016; 9:5073-80. https://doi.org/10.2147/OTT.S106574.

11. Mbatchi LC, Schmitt A, Thomas F, Cazaubon Y, Robert J, Lumbroso S, Brouillet JP, Pourquier P, Chatelut E, Boyer JC, Evrard A. Polymorphisms in SLCO1B3 and NR1I2 as genetic determinants of hematotoxicity of carboplatin and paclitaxel combination. Pharmacogenomics. 2015; 16:1439-50. https://doi.org/10.2217/pgs.15.84.

12. Gandara DR, Kawaguchi T, Crowley J, Moon J, Furuse K, Kawahara M, Teramukai S, Ohe Y, Kubota K, Williamson SK, Gautschi O, Lenz HJ, McLeod HL, et al. Japanese-US common-arm analysis of paclitaxel plus carboplatin in advanced non-small-cell lung cancer: a model for assessing population-related pharmacogenomics. J Clin Oncol. 2009; 27:3540-6. https://doi.org/10.1200/JCO.2008.20.8793.

13. Apellaniz-Ruiz M, Lee MY, Sanchez-Barroso L, GutierrezGutierrez G, Calvo I, Garcia-Estevez L, Sereno M, GarciaDonas J, Castelo B, Guerra E, Leandro-Garcia LJ, Cascon A, Johansson I, et al. Whole-exome sequencing reveals defective CYP3A4 variants predictive of paclitaxel doselimiting neuropathy. Clin Cancer Res. 2015; 21:322-8.

14. Hu L, Lv QL, Guo Y, Cheng L, Wu NY, Qin CZ, Zhou HH. Genetic variation of CYP3A5 influences paclitaxel/ carboplatin-induced toxicity in Chinese epithelial ovarian cancer patients. J Clin Pharmacol. 2016; 56:349-54. https://doi.org/10.1158/1078-0432.CCR-14-1758.

15. Green H, Soderkvist P, Rosenberg P, Mirghani RA, Rymark P, Lundqvist EA, Peterson C. Pharmacogenetic studies of Paclitaxel in the treatment of ovarian cancer. Basic Clin Pharmacol Toxicol. 2009; 104:130-7. https://doi.org/10.1111/j.1742-7843.2008.00351.x.

16. Mir O, Alexandre J, Tran A, Durand JP, Pons G, Treluyer JM, Goldwasser F. Relationship between GSTP1 Ile(105) Val polymorphism and docetaxel-induced peripheral neuropathy: clinical evidence of a role of oxidative stress in taxane toxicity. Ann Oncol. 2009; 20:736-40. https://doi.org/10.1093/annonc/mdn698.

17. Carron J, Brito AB, Torelli AC, Oliveira C, Derchain SF, Lima CS, Lourenco GJ. Association between polymorphisms in xenobiotic detoxification-related genes with prognosis of epithelial ovarian cancer. Med Oncol. 2016; 33: 112. https://doi.org/10.1007/s12032-016-0819-8.

18. Beeghly A, Katsaros D, Chen H, Fracchioli S, Zhang Y, Massobrio M, Risch H, Jones B, Yu H. Glutathione S-transferase polymorphisms and ovarian cancer treatment and survival. Gynecol Oncol. 2006; 100:330-7. https://doi.org/10.1016/j.ygyno.2005.08.035.

19. Khrunin AV, Moisseev A, Gorbunova V, Limborska S. Genetic polymorphisms and the efficacy and toxicity of cisplatin-based chemotherapy in ovarian cancer patients. Pharmacogenomics J. 2010; 10:54-61. https://doi.org/10.1038/tpj.2009.45.

20. Kang S, Ju W, Kim JW, Park NH, Song YS, Kim SC, Park SY, Kang SB, Lee HP. Association between excision repair cross-complementation group 1 polymorphism and clinical outcome of platinum-based chemotherapy in patients with epithelial ovarian cancer. Exp Mol Med. 2006; 38:320-4. https://doi.org/10.1038/emm.2006.38.

21. Krivak TC, Darcy KM, Tian C, Bookman M, Gallion $\mathrm{H}$, Ambrosone CB, Deloia JA. Single nucleotide polypmorphisms in ERCC1 are associated with disease progression, and survival in patients with advanced stage ovarian and primary peritoneal carcinoma; a Gynecologic Oncology Group study. Gynecol Oncol. 2011; 122:121-6. https://doi.org/10.1016/j.ygyno.2011.03.027.

22. Frederiks CN, Lam SW, Guchelaar HJ, Boven E. Genetic polymorphisms and paclitaxel- or docetaxel-induced toxicities: a systematic review. Cancer Treat Rev. 2015; 41:935-50. https://doi.org/10.1016/j.ctrv.2015.10.010.

23. Marsh S, Paul J, King CR, Gifford G, McLeod HL, Brown R. Pharmacogenetic assessment of toxicity and outcome after platinum plus taxane chemotherapy in ovarian cancer: the Scottish Randomised Trial in Ovarian Cancer. J Clin Oncol. 2007; 25:4528-35. https://doi.org/10.1200/JCO.2006.10.4752.

24. Low SK, Chung S, Takahashi A, Zembutsu H, Mushiroda T, Kubo M, Nakamura Y. Genome-wide association study of chemotherapeutic agent-induced severe neutropenia/ leucopenia for patients in Biobank Japan. Cancer Sci. 2013; 104:1074-82. https://doi.org/10.1111/cas.12186.

25. Ishimoto TM, Ali-Osman F. Allelic variants of the human glutathione S-transferase P1 gene confer differential cytoprotection against anticancer agents in Escherichia coli. Pharmacogenetics. 2002; 12:543-53.

26. Ketterer B. A bird's eye view of the glutathione transferase field. Chem Biol Interact. 2001; 138:27-42.

27. Johansson AS, Stenberg G, Widersten M, Mannervik B. Structure-activity relationships and thermal stability of human glutathione transferase P1-1 governed by the H-site residue 105. J Mol Biol. 1998; 278:687-98. https://doi.org/10.1006/jmbi.1998.1708.

28. Mannervik B, Danielson UH. Glutathione transferases-structure and catalytic activity. CRC Crit Rev Biochem. 1988; 23:283-337. https://doi.org/10.3109/10409238809088226.

29. Holley SL, Fryer AA, Haycock JW, Grubb SE, Strange RC, Hoban PR. Differential effects of glutathione S-transferase pi (GSTP1) haplotypes on cell proliferation and apoptosis. Carcinogenesis. 2007; 28:2268-73. https://doi.org/10.1093/carcin/bgm135.

30. Ali-Osman F, Akande O, Antoun G, Mao JX, Buolamwini J. Molecular cloning, characterization, and expression in Escherichia coli of full-length cDNAs of three human glutathione S-transferase $\mathrm{Pi}$ gene variants. Evidence for differential catalytic activity of the 
encoded proteins. J Biol Chem. 1997; 272:10004-12. https://doi.org/10.1074/jbc.272.15.10004.

31. Goto S, Iida T, Cho S, Oka M, Kohno S, Kondo T. Overexpression of glutathione S-transferase pi enhances the adduct formation of cisplatin with glutathione in human cancer cells. Free Radic Res. 1999; 31:549-58.

32. Peklak-Scott C, Smitherman PK, Townsend AJ, Morrow CS. Role of glutathione S-transferase P1-1 in the cellular detoxification of cisplatin. Mol Cancer Ther. 2008; 7:324755. https://doi.org/10.1158/1535-7163.MCT-08-0250.

33. Ishikawa T, Ali-Osman F. Glutathione-associated cisdiamminedichloroplatinum(II) metabolism and ATPdependent efflux from leukemia cells. Molecular characterization of glutathione-platinum complex and its biological significance. J Biol Chem. 1993; 268:20116-25.

34. Singh S, Okamura T, Ali-Osman F. Serine phosphorylation of glutathione S-transferase P1 (GSTP1) by PKCalpha enhances GSTP1-dependent cisplatin metabolism and resistance in human glioma cells. Biochem Pharmacol. 2010; 80:1343-55. https://doi.org/10.1016/j.bcp.2010.07.019.

35. Cheng X, Kigawa J, Minagawa Y, Kanamori Y, Itamochi H, Okada M, Terakawa N. Glutathione S-transferase-pi expression and glutathione concentration in ovarian carcinoma before and after chemotherapy. Cancer. 1997; 79:521-7. https://doi.org/10.1002/(SICI)10970142(19970201)79:3<521::AID-CNCR14>3.0.CO;2-5.

36. Chen S, Jiao JW, Sun KX, Zong ZH, Zhao Y. MicroRNA133b targets glutathione S-transferase pi expression to increase ovarian cancer cell sensitivity to chemotherapy drugs. Drug Des Devel Ther. 2015; 9:5225-35. https://doi.org/10.2147/DDDT.S87526.

37. Moyer AM, Salavaggione OE, Wu TY, Moon I, Eckloff BW, Hildebrandt MA, Schaid DJ, Wieben ED, Weinshilboum RM. Glutathione s-transferase p1: gene sequence variation and functional genomic studies. Cancer Res. 2008; 68:4791-801. https://doi.org/10.1158/0008-5472.CAN-07-6724.

38. Kim HS, Kim MK, Chung HH, Kim JW, Park NH, Song YS, Kang SB. Genetic polymorphisms affecting clinical outcomes in epithelial ovarian cancer patients treated with taxanes and platinum compounds: a Korean population-based study. Gynecol Oncol. 2009; 113:264-9. https://doi.org/10.1016/j.ygyno.2009.01.002.

39. Lambrechts S, Lambrechts D, Despierre E, Van Nieuwenhuysen E, Smeets D, Debruyne PR, Renard V, Vroman P, Luyten D, Neven P, Amant F, Leunen K, Vergote I. Genetic variability in drug transport, metabolism or DNA repair affecting toxicity of chemotherapy in ovarian cancer. BMC Pharmacol Toxicol. 2015; 16:015-0001. https://doi.org/10.1186/s40360-015-0001-5.

40. Han ZG, Tao J, Yu TT, Shan L. Effect of GSTP1 and ABCC2 Polymorphisms on Treatment Response in Patients with Advanced Non-Small Cell Lung Cancer Undergoing Platinum-Based Chemotherapy: A Study in a Chinese
Uygur Population. Med Sci Monit. 2017; 23:1999-2006. https://doi.org/10.12659/MSM.904156.

41. Li QF, Yao RY, Liu KW, Lv HY, Jiang T, Liang J. Genetic polymorphism of GSTP1: prediction of clinical outcome to oxaliplatin/5-FU-based chemotherapy in advanced gastric cancer. J Korean Med Sci. 2010; 25:846-52. https://doi.org/10.3346/jkms.2010.25.6.846.

42. Burger RA, Brady MF, Bookman MA, Fleming GF, Monk BJ, Huang H, Mannel RS, Homesley HD, Fowler J, Greer BE, Boente M, Birrer MJ, Liang SX, et al. Incorporation of bevacizumab in the primary treatment of ovarian cancer. N Engl J Med. 2011; 365:2473-83. https://doi.org/10.1056/NEJMoa1104390.

43. Harris M, Bhuvaneshwar K, Natarajan T, Sheahan L, Wang D, Tadesse MG, Shoulson I, Filice R, Steadman K, Pishvaian MJ, Madhavan S, Deeken J. Pharmacogenomic characterization of gemcitabine response--a framework for data integration to enable personalized medicine. Pharmacogenetics and genomics. 2014; 24:81-93. https://doi.org/10.1097/FPC.0000000000000015.

44. Ananthakrishnan AN, Khalili H, Song M, Higuchi LM, Lochhead P, Richter JM, Chan AT. Genetic Polymorphisms in Fatty Acid Metabolism Modify the Association Between Dietary n3: n6 Intake and Risk of Ulcerative Colitis: A Prospective Cohort Study. Inflamm Bowel Dis. 2017; 23:1898-1904. https://doi.org/10.1097/MIB.0000000000001236.

45. Aslibekyan S, Kabagambe EK, Irvin MR, Straka RJ, Borecki IB, Tiwari HK, Tsai MY, Hopkins PN, Shen J, Lai CQ, Ordovas JM, Arnett DK. A genome-wide association study of inflammatory biomarker changes in response to fenofibrate treatment in the Genetics of Lipid Lowering Drug and Diet Network. Pharmacogenetics and genomics. 2012; 22:191197. https://doi.org/10.1097/FPC.0b013e32834fdd41.

46. Zhang JE, Klein K, Jorgensen AL, Francis B, Alfirevic A, Bourgeois S, Deloukas P, Zanger UM, Pirmohamed M. Effect of Genetic Variability in the CYP4F2, CYP4F11, and CYP4F12 Genes on Liver mRNA Levels and Warfarin Response. Frontiers in pharmacology. 2017; 8:323. https://doi.org/10.3389/fphar.2017.00323.

47. Cauffiez C, Klinzig F, Rat E, Tournel G, Allorge D, Chevalier D, Pottier N, Lovecchio T, Colombel JF, Lhermitte M, Lo-Guidice JM, Broly F. Human CYP4F12 genetic polymorphism: identification and functional characterization of seven variant allozymes. Biochemical pharmacology. 2004; 68:2417-2425. https://doi.org/10.1016/j.bcp.2004.08.025.

48. Zheng L, Li X, Meng X, Chou J, Hu J, Zhang F, Zhang Z, Xing Y, Liu Y, Xi T. Competing endogenous RNA networks of CYP4Z1 and pseudogene CYP4Z2P confer tamoxifen resistance in breast cancer. Mol Cell Endocrinol. 2016; 427:133-142. https://doi.org/10.1016/j.mce.2016.03.012.

49. Buxton JA, Omura J, Kuo M, Ross C, Tzemis D, Purssell R, Gardy J, Carleton B. Genetic determinants of cocaineassociated agranulocytosis. BMC research notes. 2015; 8:240. https://doi.org/10.1186/s13104-015-1219-4. 
50. Lee SJ, Perera L, Coulter SJ, Mohrenweiser HW, Jetten A, Goldstein JA. The discovery of new coding alleles of human CYP26A1 that are potentially defective in the metabolism of all-trans retinoic acid and their assessment in a recombinant cDNA expression system. Pharmacogenetics and genomics. 2007; 17:169-180. https://doi.org/10.1097/FPC.0b013e32801152d6.

51. Warpman Berglund U, Sanjiv K, Gad H, Kalderen C, Koolmeister T, Pham T, Gokturk C, Jafari R, Maddalo G, Seashore-Ludlow B, Chernobrovkin A, Manoilov A, Pateras IS, et al. Validation and development of MTH1 inhibitors for treatment of cancer. Annals of oncology. 2016; 27:2275-2283. https://doi.org/10.1093/annonc/mdw429.

52. Sakai Y, Oda H, Yoshimura D, Furuichi M, Kang D, Iwai S, Hara T, Nakabeppu Y. The GT to GC single nucleotide polymorphism at the beginning of an alternative exon 2C of human MTH1 gene confers an amino terminal extension that functions as a mitochondrial targeting signal. J Mol Med (Berl). 2006; 84:660-670. https://doi.org/10.1007/s00109-006-0053-5.

53. Pan W, Song IS, Shin HJ, Kim MH, Choi YL, Lim SJ, Kim WY, Lee SS, Shin JG. Genetic polymorphisms in $\mathrm{Na}$-taurocholate co-transporting polypeptide (NTCP) and ileal apical sodium-dependent bile acid transporter (ASBT) and ethnic comparisons of functional variants of NTCP among Asian populations. Xenobiotica. 2011; 41:501-510. https://doi.org/10.3109/00498254.2011.555567.

54. Lu XF, Zhou Y, Bi KS, Chen XH. Mixed effects of OATP1B1, BCRP and NTCP polymorphisms on the population pharmacokinetics of pravastatin in healthy volunteers. Xenobiotica. 2016; 46:841-849. https://doi.org/10.3109/00498254.2015.1130881.

55. Emami Riedmaier A, Burk O, van Eijck BA, Schaeffeler E, Klein K, Fehr S, Biskup S, Muller S, Winter S, Zanger UM, Schwab M, Nies AT. Variability in hepatic expression of organic anion transporter 7/SLC22A9, a novel pravastatin uptake transporter: impact of genetic and regulatory factors. Pharmacogenomics J. 2016; 16:341-351. https://doi.org/10.1038/tpj.2015.55.
56. Ahn SK, Suh CK, Cha SH. Polymorphisms of SLC22A9 (hOAT7) in Korean Females with Osteoporosis. Korean J Physiol Pharmacol. 2015; 19:319-325. https://doi.org/10.4196/kjpp.2015.19.4.319.

57. Owen RP, Lagpacan LL, Taylor TR, De La Cruz M, Huang CC, Kawamoto M, Johns SJ, Stryke D, Ferrin TE, Giacomini KM. Functional characterization and haplotype analysis of polymorphisms in the human equilibrative nucleoside transporter, ENT2. Drug Metab Dispos. 2006; 34:12-15. https://doi.org/10.1124/dmd.105.006270.

58. Chen X, Zhang L, Ren S, Li X, Zhou F, Li W, Gao G, He Y, Zhou C. Genomic polymorphisms of SLC29A3 associated with overall survival in advanced non-small-cell lung cancer treated with gemcitabine. Med Oncol. 2014; 31:865. https://doi.org/10.1007/s12032-014-0865-z.

59. Lima A, Bernardes M, Azevedo R, Monteiro J, Sousa H, Medeiros R, Seabra V. SLC19A1, SLC46A1 and SLCO1B1 polymorphisms as predictors of methotrexate-related toxicity in Portuguese rheumatoid arthritis patients. Toxicol Sci. 2014; 142:196-209. https://doi.org/10.1093/toxsci/kfu162.

60. Li H, Durbin R. Fast and accurate long-read alignment with Burrows-Wheeler transform. Bioinformatics. 2010; 26:58995. https://doi.org/10.1093/bioinformatics/btp698.

61. McKenna A, Hanna M, Banks E, Sivachenko A, Cibulskis K, Kernytsky A, Garimella K, Altshuler D, Gabriel S, Daly M, DePristo MA. The Genome Analysis Toolkit: a MapReduce framework for analyzing next-generation DNA sequencing data. Genome Res. 2010; 20:1297-303. https://doi.org/10.1101/gr.107524.110.

62. Hwang S, Kim E, Lee I, Marcotte EM. Systematic comparison of variant calling pipelines using gold standard personal exome variants. Sci Rep. 2015; 5:17875. https://doi.org/10.1038/srep17875.

63. Purcell S, Neale B, Todd-Brown K, Thomas L, Ferreira MA, Bender D, Maller J, Sklar P, de Bakker PI, Daly MJ, Sham PC. PLINK: a tool set for whole-genome association and population-based linkage analyses. Am J Hum Genet. 2007; 81:559-75. https://doi.org/10.1086/519795. 